\title{
Assessment of the Patient's Perception Regarding Triple Vessel Disease and its Management
}

\author{
Vrushali P. Dighikar and Seema Singh \\ Smt. Radhikabai Meghe Memorial College of Nursing, Datta Meghe Institute of \\ Medical Sciences, Sawangi (Meghe), Wardh, India \\ Corresponding author email: pujadighikar@gmail.com
}

\section{ABSTRACT}

Triple vessel disease is a type of coronary artery disease that is very severe. Coronary artery disease develops when the major blood arteries become damaged. To determine the patient's perception of living with triple vessel disease and its management. To associate the demographic variable with patient's perception regarding triple vessel disease and its management. A descriptive research approach were used. A cross-sectional study design was applied. Samples comprised of 45 subjects including both males and females. The research was carried out in a hospital in Sawangi (M), Wardha. A structure demographic sheet revealing age, gender, education, monthly family income, bad habits, any disease along with structured perception scale was used. Descriptive and inferential statistics were used in the analysis. The findings of the study revealed that $22.22 \%$ of the patients were disagreed about perception about triple vessel disease, $37.78 \%$ were agreed and 60\% strongly agreed for perception about triple vessel disease. That means none of the patients $(0 \%)$ had strongly negative perception, $22.22 \%$ had negative perception, $37.78 \%$ of patient had positive perception and $40 \%$ patients had strongly positive perception. Also, the study found out the statistical association of perception score with age, education, monthly family income and any diseases. The majority of patients had positive and good perception regarding triple vessel disease but not aware about the management of triple vessel disease. Age, education, occupation and history of any disease had positive effect on perception.

\section{KEY WORDS: ASSESS, TRIPLE VESSEL DISEASE, PERCEPTION, MANAGEMENT.}

\section{INTRODUCTION}

In most age groups, heart disease is the main cause of death, accounting for one out of every four deaths. Coronary artery disease is the leading cause of death in both men and women around the world. Coronary artery disease (also known as ischemic heart disease) is described as "Impairment of cardiac function caused by obstructive alterations in the coronary circulation to the heart, resulting in insufficient blood flow to the heart relative to its needs." Coronary artery disease affects an estimated 4.5 million persons in India. coronary artery

Biosc Biotech Res Comm P-ISSN: 0974-6455 E-ISSN: 2321-4007

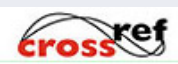

Identifiers and Pagination

Year: 2021 Vol: 14 No (9) Special Issue

Pages: $174-179$

This is an open access article under Creative

Commons License Attribn 4.0 Intl (CC-BY).

DOI: http://dx.doi.org/10.21786/bbrc/14.9.33 disease (CAD) is the most common type of heart disease, affecting around 6.7 percent of people over the age of 20. Within CAD lies an extreme form, Triple Vessel Disease that affects a smaller number of patients. It is an extreme form of coronary artery disease. When the major blood vessels become damage that time coronary artery disease developed (Al Khayyal et al., 2016).

There is main two causes of coronary artery disease that are Plaque (cholesterol deposits) and inflammation. While minor plaque deposits may not obstruct blood flow to the heart, bigger plaque deposits might reduce or even restrict blood flow to the heart. These blockages can result in chest discomfort, shortness of breath, or even a heart attack. While most CAD affects only one of the major coronary arteries, triple vascular disease affects all three major blood vessels that supply blood to the heart (left anterior descending, left circumflex, right coronary artery). The left ventricle's contractile activity is likewise impaired. According to several research, around 26-33 
percent of all CAD patients will develop triple vessel disease. This means that one out of every eight males and one out of every twelve women will develop TVD over their lives (Umuerri 2020).

The recent statistics shows that Around 50 percent of the three-vessel disease patients died before the completion of the study. The rate of 5-year survival was $88 \%$. Sometimes motivated by insufficient compliance, HF hospitalizations and readmissions continue to increase. We explored the idea that compliance and outcome could be influenced by the understanding of the patient of their illness. The blood supply to the heart comes from the Right Coronary Artery (RCA) and the Left Coronary Artery - the first two branches of the aorta in the Sinus of Valsalva. The Left Coronary Artery is quite short (often called the Left Main Stem) and divides into the Left Anterior Descending artery (LAD) and the Circumflex artery (LCX). Triple vessel disease is the term used for atherosclerotic narrowing of the three major blood vessels of the heart (RCA, LAD and LCx). Severe triple vessel disease and Left Main Stem stenosis are both associated with imminent myocardial infarction, and so if present surgical (or percutaneous) intervention is recommended. In the proximal or middle section of all three arteries, a 70 per cent reduction in luminal diameter is needed to classify as a three-vessel disease.

Triple vessel disease can be prevented by focusing on how the patients perceived. The main objective of the lifestyle modification is to return the patient to an optimal level of physiological, psychological and vocational functioning as to prevent the progression of ischemic heart disease. A combination of exercise, education in psychological rehabilitation seems to be the most important improvement in life style and requires longterm maintenance of modified habits. There is substantial evidence that correct information guidance during their recovery in wards is one of the most important aspects of nursing and it can be continued even after discharged.

\section{The Study's Objectives}

1. To determine the patient's perception of living with triple vessel disease and its management.

2. To associate the demographic variable with patient's perception regarding triple vessel disease and its management.

\section{MATERIAL AND METHODS}

A descriptive research approach was used. A crosssectional study design was applied. Samples comprised of 45 subjects including both males and females. Setting of the study was patients with triple vessel disease from selected hospital Sawangi (Meghe), Wardha. The target group of this study was triple-vessel disease patients. Triple vessel disease patients who meet the inclusion and exclusion criteria were sampled in this study. In this study sample size was 45 patients were selected purposively to suit the study. The Non-Probability Purposive Sampling Methodology was the sampling method used in the analysis. Inclusion criteria of the study was 1 . Patients who are diagnosed with triple vessel disease 2. Patients who are willing to engage in the research. 3. Patients who are present during the data collection process. Exclusion criteria of study was 1. Patients who have already attended a similar type of study. 2. Patients who are critically ill. The following tools developed for the study. a) Structured response sheet for Demographic data, which gives baseline information such as, Age, Gender, Education, Monthly Family Income, Bad habits, any disease etc. b) 5- point Likert scale related to patient' perception regarding triple vessel disease and its management.

Table 1. Percentage wise distribution of patients according to their demographic characteristics $n=45$

\begin{tabular}{|c|c|c|}
\hline $\begin{array}{l}\text { Demographic } \\
\text { Variables }\end{array}$ & $\begin{array}{c}\text { No. of } \\
\text { patients }\end{array}$ & $\begin{array}{c}\text { Percentage } \\
(\%)\end{array}$ \\
\hline \multicolumn{3}{|l|}{ Age(yrs) } \\
\hline $51-60$ yrs & 26 & 57.8 \\
\hline $61-70$ yrs & 15 & 33.3 \\
\hline $71-80$ yrs & 4 & 08.9 \\
\hline \multicolumn{3}{|l|}{ Gender } \\
\hline Male & 28 & 62.2 \\
\hline Female & 17 & 37.8 \\
\hline \multicolumn{3}{|l|}{ Education } \\
\hline Illiterate & 2 & 04.5 \\
\hline Primary & 20 & 44.4 \\
\hline Secondary & 15 & 33.3 \\
\hline Graduate and above & 8 & 17.8 \\
\hline \multicolumn{3}{|l|}{ Monthly family income } \\
\hline$\leq 5000 \mathrm{Rs}$ & 7 & 15.6 \\
\hline 5001-10000 Rs & 16 & 35.6 \\
\hline $10001-15000 \mathrm{Rs}$ & 10 & 22.1 \\
\hline $15001-20000 \mathrm{Rs}$ & 12 & 26.7 \\
\hline >20000 Rs & 0 & 00.0 \\
\hline \multicolumn{3}{|l|}{ Bad Habits } \\
\hline Smoking & 0 & 00.0 \\
\hline Drinking & 5 & 11.1 \\
\hline Tobacco Chewing & 16 & 35.6 \\
\hline Others & 9 & 20.0 \\
\hline No Any & 15 & 33.3 \\
\hline \multicolumn{3}{|l|}{ Any Disease } \\
\hline Diabetes & 4 & 08.9 \\
\hline High BP & 18 & 40.0 \\
\hline High blood cholesterol & 6 & 13.3 \\
\hline Both $\mathrm{A}$ and $\mathrm{B}$ & 16 & 35.6 \\
\hline Others & 1 & 02.2 \\
\hline
\end{tabular}

RESULTS AND DISCUSSION

The findings of the study revealed that given in the following. 
The above table no. 1 shows that the frequency of patients $26(57.8 \%)$ were in the age group of 51-60 years, $15(33.3 \%)$ were in the age group of $61-70$ years and $4(08.9 \%)$ of them were in the age group of 71-80 years. The frequency of patients $28(62.2 \%)$ were males and $17(37.8 \%)$ of them were females. The frequency of patients $2(04.5 \%)$ were illiterate, $20(44.4 \%)$ were educated up to primary, $15(33.3 \%)$ were educated up to secondary and $8(17.8 \%)$ of them were graduates and above. the frequency of patients $7(15.6 \%)$ had monthly family income of less than 5000 Rs, 16(35.6\%) had between 5001-10000 Rs, $10(22.1 \%)$ had between 10001-15000 Rs, $12(26.7 \%)$ of them had monthly family income of 15001-20000 Rs, and $0(0 \%)$ of them had more than 20,000 Rs. The frequency of patients5(11.1\%) had habits of drinking, 16(35.6\%) had habits of tobacco chewing, $9(20 \%)$ had other habit and $15(33.30 \%)$ of them had no habit. frequency of patients $4(08.9 \%)$ had history of diabetes, $18(40 \%)$ had history of high blood pressure, 6(13.3\%) had history of high blood cholesterol, 16(35.6\%) had history of diabetes and high blood pressure and $1(02.2 \%)$ had other history.

\begin{tabular}{|l|c|c|c|}
\hline \multirow{2}{*}{ Table 2. Assessment with level of perception score } \\
\hline \multirow{2}{*}{ Level of perception } & & \multicolumn{3}{|c|}{ Level of perception Score } \\
\cline { 3 - 4 } & \multirow{2}{*}{ Score Range } & No of patients & Percentage \\
\hline Neutral & 0 & 0 & 00.00 \\
\hline Strongly Disagree & $0-25 \%$ & 0 & 00.00 \\
\hline Disagree & $26-50 \%$ & 10 & 22.22 \\
\hline Agree & $51-75 \%$ & 17 & 37.78 \\
\hline Strongly Agree & $76-100 \%$ & 18 & 40.00 \\
\hline Minimum score & & \multicolumn{3}{|c|}{38} \\
\hline Maximum score & & \multicolumn{3}{|c|}{$63.20 \pm 17.36$} \\
\hline Mean perception score & & \multicolumn{3}{|c|}{} \\
\hline
\end{tabular}

Figure 1: Assessment with level of perception score

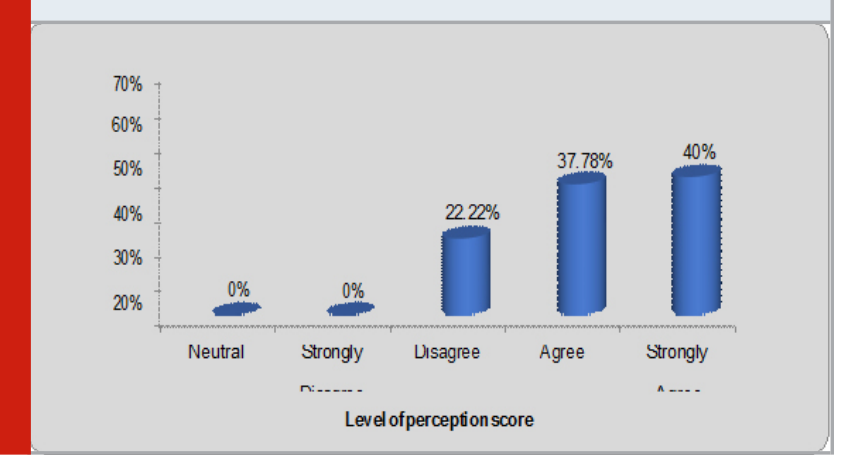

The above table no.2 and figure no. 1 shows that the frequency of patients $10(22.22 \%)$ of were disagreed about perception regarding triple vessel disease and its management, 17(37.78\%) were agreed and 189(40\%) strongly agreed for perception regarding triple vessel disease and its management. Minimum perception score was 38 and maximum perception score was 89 . Mean perception score was $63.20 \pm 17.36$.

The above table no. 3 depicts the association of perception score with age in years of patients regarding triple vessel disease and its management. The calculated 'F,' i.e., 4.58 at a 5\% level of significance, was substantially lower than the tabulated ' $F$,' which was $3.15(\mathrm{df}=2,42)$. Also, the calculated ' $p$ ' $=0.016$, which was much lower than the acceptable level of significance of ' $p$ ' $=0.05$. As a result, it's assumed that a patient's age in years is statistically related to their perception score.

The relationship between a patient's perception score and their gender when it comes to triple vascular disease and its treatment. The calculated ' $\mathrm{t}$ ' was 1.25 at a $5 \%$ level of significance, however the tabulated ' $t$ ' values were $2.02(\mathrm{df}=33)$, which is substantially higher than the calculated ' $t$ ' of 1.25. Furthermore, the calculated ' $p$ ' $=0.21$ was much greater than the allowed level of significance, which was ' $p$ ' $=0.05$. As a result, it's assumed that a patient's gender has no statistical bearing on their perception score. The relationship between a patient's perception score and their level of education when it comes to triple vascular disease and its treatment. The calculated 'F,' i.e., 49.61 at a 5\% level of significance, was substantially lower than the tabulated ' $F$,' which was 2.76 $(\mathrm{df}=3,41)$. Furthermore, the calculated ' $p$ ' $=0.0001$ was significantly below than the accepted level of significance, which was ' $p$ ' $=0.05$. As a result, it's assumed that a patient's educational level is statistically related to their perception score.

The association between a patient's perception score and their monthly family income (Rs) when it comes to triple vascular disease and its treatment. The computed 'F,' i.e., 83.79 at a $5 \%$ level of significance, was substantially lower than the tabulated 'F', which was $2.76(\mathrm{df}=3,41)$. Furthermore, the computed ' $p$ ' $=0.0001$ was much lower 
than the accepted level of significance, i.e. ' $p$ ' $=0.05$. As a result, it's assumed that patients' monthly family income (Rs) is statistically related to their perception score.

The association between a patient's perception score and their bad habits when it comes to triple vascular disease and its treatment. The estimated 'F,' i.e. 2.77 at a 5\% level of significance, was substantially higher than the tabulated 'F,' i.e. 2.76( $\mathrm{df}=3,41)$. Furthermore, the determined ' $p$ ' $=0.054$ was significantly greater than the permissible level of significance, which was 'p' $=0.05$. As a result, it is determined that patients' bad habits are statistically unrelated to their perception score.

\begin{tabular}{|c|c|c|c|c|c|}
\hline $\begin{array}{l}\text { Demographic } \\
\text { Variables }\end{array}$ & $\begin{array}{c}\text { No. of } \\
\text { Patients }\end{array}$ & Mean \pm SD & df & $\begin{array}{l}\text { F-value/ } \\
\text { t- value }\end{array}$ & p-value \\
\hline $\begin{array}{l}\text { Age(yrs) } \\
51-60 \text { yrs }\end{array}$ & 26 & $66.38 \pm 14.95$ & 2,42 & 4.58 & $\begin{array}{c}0.016 \\
S, p<0.05\end{array}$ \\
\hline $\begin{array}{l}61-70 \text { yrs } \\
71-80 \text { yrs }\end{array}$ & $\begin{array}{c}15 \\
4\end{array}$ & $\begin{array}{c}63.80 \pm 19.42 \\
40.25 \pm 2.06\end{array}$ & & & \\
\hline Gender & & & & & \\
\hline Male & 28 & $65.71 \pm 15.81$ & 33 & 1.25 & $\begin{array}{c}0.21 \\
N S, p>0.05\end{array}$ \\
\hline $\begin{array}{l}\text { Female } \\
\text { Education } \\
\text { Illiterate }\end{array}$ & $\begin{array}{l}17 \\
2\end{array}$ & $\begin{array}{c}59.05 \pm 19.43 \\
38 \pm 0\end{array}$ & 3,41 & 49.61 & $\begin{array}{c}0.0001 \\
S, p<0.05\end{array}$ \\
\hline $\begin{array}{l}\text { Primary } \\
\text { Secondary } \\
\text { Graduate and above }\end{array}$ & $\begin{array}{c}20 \\
15 \\
8\end{array}$ & $\begin{array}{l}48.85 \pm 8.94 \\
76.66 \pm 8.39 \\
80.12 \pm 7.14\end{array}$ & & & \\
\hline $\begin{array}{l}\text { Monthly Family income } \\
\leq 5000 \text { Rs }\end{array}$ & 7 & $38.57 \pm 0.97$ & 3,41 & 83.79 & $\begin{array}{c}0.0001 \\
S, p<0.05\end{array}$ \\
\hline $\begin{array}{l}\text { 5001-10000 Rs } \\
10001-15000 \mathrm{Rs} \\
15001-20000 \mathrm{Rs} \\
>20000 \mathrm{Rs} \\
\text { Bad habits } \\
\text { Smoking }\end{array}$ & $\begin{array}{c}16 \\
10 \\
12 \\
0\end{array}$ & $\begin{array}{c}52.87 \pm 7.74 \\
74.70 \pm 9.05 \\
81.75 \pm 4.43 \\
0 \pm 0 \\
0 \pm 0\end{array}$ & 3,41 & 2.77 & $\begin{array}{c}0.054 \\
N S, p>0.05\end{array}$ \\
\hline $\begin{array}{l}\text { Drinking } \\
\text { Tobacco Chewing } \\
\text { Others } \\
\text { No Any }\end{array}$ & $\begin{array}{c}5 \\
16 \\
9 \\
15\end{array}$ & $\begin{array}{c}50.80 \pm 17.52 \\
68.81 \pm 12.60 \\
54 \pm 17.22 \\
66.86 \pm 18.97\end{array}$ & & & \\
\hline Any disease & & & & & \\
\hline $\begin{array}{l}\text { Diabetes } \\
\text { High BP } \\
\text { High blood cholesterol } \\
\text { Both A and B } \\
\text { Others }\end{array}$ & $\begin{array}{c}4 \\
\\
18 \\
6 \\
16 \\
1\end{array}$ & $\begin{array}{c}70.25 \pm 12.17 \\
47.50 \pm 7.60 \\
76.16 \pm 10.92 \\
75 \pm 14.64 \\
51 \pm 0\end{array}$ & 4,41 & 15.30 & $\begin{array}{c}0.0001 \\
S, p<0.05\end{array}$ \\
\hline
\end{tabular}

The association between a patient's perception score and the types of disease they have in terms of triple vascular disease and how it is managed. The calculated 'F,' i.e., 15.30 at a $5 \%$ level of significance, was substantially lower than the tabulated 'F,' i.e., 2.61 $(\mathrm{df}=4,41)$.
Furthermore, the computed ' $p$ ' $=0.0001$ was much lower than the accepted level of significance, i.e., 'p'=0.05. As a result, it's assumed that a patient's habit is statistically linked to their perception score. 


\section{DISCUSSION}

The study's findings were reviewed in relation to the aims, theoretical foundation, and hypothesis, as well as the findings of other research in this section. The purpose of this study was to determine how patients felt about triple vessel disease and how it was managed.

The table no.2 shows that patient's perception score regarding triple vessel disease and its management was $22.22 \%$ of the patients were disagreed about perception regarding triple vessel disease and its management, $37.78 \%$ were agreed and 40\% strongly agreed for perception regarding triple vessel disease and its management. Minimum perception score was 38 and maximum perception score was 89 . Mean perception score was $63.20 \pm 17.36$. The present study indicated that patients had good means positive perception regarding triple vessel disease except management.

One similar study conducted on "Perception and behavior in patients with coronary heart disease about risk factors and life style modification in tertiary care hospital, Bhavnagar" Among Patients of coronary heart disease attending OPD in tertiary care hospital, Bhavnagar. 174 samples are included in the study, the researcher used a cross-sectional study design with a questionnaire that included personal details, BMI, history of risk factors, behaviour improvement, and medical counselling. Epi info evaluated the data and applied the appropriate statistical tests. The results showed that a total of 73 patients were addicted to either tobacco or alcohol. Addiction lasted an average of 22.43 years. Doctors gave therapy to 94 percent of patients at the time of their illness. Counselling about illness, risk factors, and lifestyle change had a positive effect on 96 percent of patients, with just 4\% needing more counselling in the future. In this study indicated that patients had good perception about all risk factors except stress and sedentary life style. In my study also patients are strongly agreed about the perception of triple vessel disease but they are not aware about the management of triple vessel disease.

A study conducted on "Public knowledge and perception of heart disease: A cross- sectional study of two communities in Delta State, Nigeria" The study questionnaire was adapted from the heart disease fact questionnaire (HDFQ). Respondents with knowledge scores $<50 \%, 50-69.9 \%$, and $\geq 70 \%$ were assigned poor, moderate, and good knowledge, respectively. Eight hundred and sixty-six adults with a mean age of 42.6 years were recruited for the study. Majority (56.0\%) of the respondents were females and urban dwellers. Knowledge score ranged between $0.0 \%$ and $95.7 \%$ with a mean score of 39.8( \pm 22.5$) \%$. Majority (65.1\%) had poor knowledge of heart disease. Knowledge of heart disease was significantly associated with place of residence [OR $(95 \% \mathrm{CI})=0.544(0.408-0.727) ; \mathrm{P}<0.001]$, age group [OR $(95 \% \mathrm{CI})=0.437(0.314-0.607) ; \mathrm{P}<0.001]$, duration of formal education [OR $(95 \% \mathrm{CI})=3.805(2.755-5.255)$; $\mathrm{P}<0.001]$ but not sex $(\mathrm{P}=0.871)$. Majority $(75.2 \%)$ perceived heart disease to be an extremely serious condition. However, $74.7 \%$ of the respondents were not concerned at all about getting heart disease. The association between knowledge of heart disease and place of residence, age group, sex, duration of formal education, and marital status is as shown in Table. The associations were statistically significant, except for sex where there were no observed differences in knowledge. In present study also age is statistically associated with perception but not with gender.

A study conducted on "Elders' Knowledge About Risk Factors of Coronary Heart Disease, Their Perceived Risk, and Adopted Preventive Behaviors" a researcher uses a descriptive research design. The research study was conducted in four governmental and two private elderly homes in Alexandria, Egypt, which were chosen at random by ballot out of all the elderly homes in Alexandria. There were 150 participants in the sample. The findings revealed a correlation between educational level and mean scores on CHD risk factors, risk perception, and preventive behaviors adoption. The elders' educational level was found to have a substantial relationship with their awareness of CHD risk factors, risk perception, and adopted preventive behaviors, with $\mathrm{p}=0.000^{*}, \mathrm{p}=0.017^{*}$, and $\mathrm{p}=0.000^{*}$, respectively.

The higher the educational level, the greater the increase in knowledge of CHD risk factors, risk perception, and adopted preventive behaviors. The degree of education was found to be positively and substantially linked to the perception of CHD risk in the report. As a result, they conclude that having a high level of education and knowing someone who has CHD has a positive influence on awareness, risk perception, and preventive behaviors adoption. In this study education was statistically associated with perception score and in present study also the education was statistically associated.

From May 2015 to February 2016, a cross-sectional study was done on a population with three-vessel coronary artery disease. There were 100 patients in the study, 75 of whom were male (mean age 639) and 25 of whom were female (mean age 699) years old. Diabetes (58 percent), hypertension (86 percent), smoking (68 percent), dyslipidemia (100 percent), metabolic syndrome (71 percent), and obesity/overweight were all found to be coronary risk factors (75 percent). Women had a higher prevalence of diabetes and metabolic syndrome $(\mathrm{p}=0.03)$, but men had a higher prevalence of smoking (76 percent, $\mathrm{p}=0.003$ ). 
In 58 percent of patients, the Ankle-Brachial Index was abnormal, the mean Syntax score was 36.911.5, and the prevalence of left main coronary heart disease was 36 percent. The significant incidence of coronary risk factors in this group of individuals with complicated coronary lesions could indicate a worse prognosis. Because hypertension, diabetes, and high blood cholesterol are major risk factors for triple vascular disease, the presence of any disease history, such as hypertension, diabetes, and high blood cholesterol, is associated with perception score in this study.

\section{CONCLUSION}

The researcher, conducted a descriptive research on the topic assess the patient's perception regarding triple vessel disease and its management. The researcher aimed to improve the level of perception of triple vessel disease patients she predetermined certain objectives, to precede the study. Those objectives were adequate to reach into the findings. A particular time period has been allocated for each step. Investigator had presented her hypothetical views about the study in its beginning. And finally, the researcher reached into her findings. The result of this study shows that, $22.22 \%$ of the patients were disagreed about perception about triple vessel disease, 37.78\% were agreed and 60\% strongly agreed for perception about triple vessel disease.

To assess the patient's perception regarding triple vessel

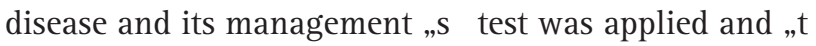
value was calculated, Minimum perception score was 38 and maximum perception score was 89 . Mean perception score was $63.20 \pm 17.36$. That means $0 \%$ patients are having strongly negative perception, $22.22 \%$ are having negative perception, $37.78 \%$ of patient are having positive perception and 40\% patients are having strongly positive perception. Thus, it concludes that patient had good and positive perception regarding triple vessel disease but not aware about the management of triple vessel disease. Age, education, occupation and history of any disease had positive effect on perception.

\section{REFERENCES}

Ajitha E. A study to evaluate the impact of instructional module on coronary artery disease risk factors in assessing knowledge and perception among adults at selected villages in Madurai (Doctoral dissertation, CSI Jeyaraj Annapackiam College of Nursing, Madurai). Al Khayyal H, El Geneidy M, El Shazly SA. (2016) Elders' Knowledge about Risk Factors of Coronary Heart Disease, Their Perceived Risk, and Adopted Preventive Behaviors. Journal of Education and Practice. ;7(10):8998.

Arroyo-Rodríguez C, Brito-Zurita OR, SandovalNavarrete S, Solis-Vásquez R, Ornelas-Aguirre JM, Olea-Hernández C, Vásquez-Serna C, Castelan-Ojeda AM. (2018) Risk factors for three-vessel coronary artery disease in patients of Northwest Mexico. Archivos de cardiología de México. ;88(5):423-31

Chauhan PA, Trivedi A. Study of perception and behaviour in patients with coronary heart disease about risk factors and life style modification in tertiary care hospital, Bhavnagar

Mahalakshmi G. A study to evaluate the effectiveness of video assisted teaching programme on knowledge regarding cardiac rehabilitation among post myocardial infarction patients admitted in Cardiac in-patient department at selected Cardiac Hospital, Erode (dt) (Doctoral dissertation, Vivekanandha College of Nursing, Tiruchengodu).

Triple Vessel Disease: Pathology, Diagnosis and Treatment. Digirad. 2020.

Umuerri EM. (2020). Public knowledge and perception of heart disease: A cross- sectional study of two communities in Delta State, Nigeria. Journal of Medicine in the Tropics. Jan 1;22(1):65 